\title{
The use of diffuse reflectance infrared spectroscopy to monitor the oxidation of UV irradiated and naturally aged bitumen and asphalt
}

Article

Accepted Version

Bowden, H., Almond, M. J., Hayes, W., Browne, C. and McRobbie, S. (2021) The use of diffuse reflectance infrared spectroscopy to monitor the oxidation of UV irradiated and naturally aged bitumen and asphalt. Road Materials and Pavement Design, 22 (6). pp. 1254-1267. ISSN 1468-0629 doi: https://doi.org/10.1080/14680629.2019.1684982 Available at https://centaur.reading.ac.uk/86924/

It is advisable to refer to the publisher's version if you intend to cite from the work. See Guidance on citing.

To link to this article DOI: http://dx.doi.org/10.1080/14680629.2019.1684982

Publisher: Taylor \& Francis

All outputs in CentAUR are protected by Intellectual Property Rights law, including copyright law. Copyright and IPR is retained by the creators or other copyright holders. Terms and conditions for use of this material are defined in the End User Agreement. 


\section{www.reading.ac.uk/centaur}

\section{CentAUR}

Central Archive at the University of Reading

Reading's research outputs online 


\title{
The Use of Diffuse Reflectance Infrared Spectroscopy to Monitor the Oxidation of UV Irradiated and Naturally Aged Bitumen and Asphalt
}

\author{
H. Bowden, ${ }^{a}$ M.J. Almond, ${ }^{a^{*}}$ W. Hayes, ${ }^{a}$ S. McRobbie ${ }^{b}$ \\ ${ }^{a}$ University of Reading, Whiteknights, Reading, UK \\ ${ }^{\mathrm{b}}$ Transport Research Laboratory, Crowthorne House, Crowthorne, UK \\ *m.j.almond@reading.ac.uk
}

\begin{abstract}
A total of $£ 4.2$ billion was spent repairing roads in England between the years 2013-14. [1] At present road surface quality is monitored visually and then the road is repaired where damage arises. By the time the road surface is visibly damaged it is beyond repair and thus requires resurfacing. This road maintenance regime is a very costly and time consuming. As a consequence the ability to monitor and predict road surface degradation based on noninvasive measurements can provide a significant advance in highway maintenance.

The oxidation of the bitumen in the road surface is known to promote failure of the road surface as it reduces the cohesion between the bitumen and the aggregate. This paper reports the use of non-contact, diffuse reflectance infrared Fourier transfer (DRIFT) spectroscopy to monitor the oxidation process in bitumen and asphalt.

The results described in this paper outline the comparison between natural ageing and enhanced, artificially-promoted ageing of bitumen and asphalt samples using UV light. The IR spectroscopic results show the evolution of oxidation product functional groups and allow the ageing of the bitumen and asphalt samples to be monitored.
\end{abstract}

\section{Keywords}

Asphalt, ageing, bitumen, UV light, FTIR spectroscopy, diffuse reflectance, DRIFT spectroscopy

\section{Introduction}

Asphalt pavements (road surfaces) are composed of bitumen, filler (commonly calcium carbonate), and aggregates. [2] The bitumen acts as an adhesive that when mixed with filler, binds aggregates to make up the bulk of the pavement.

Bitumen is composed of hydrocarbon chains of varying length, with heteroatoms such as oxygen, sulfur and nitrogen within the structure. [3] The chemical ageing of bitumen involves the oxidation of the unsaturated hydrocarbon components of the bitumen. This oxidation is said to be one of the main factors contributing to bitumen hardening upon ageing and has been analysed extensively. [4]

Elevated oxygen levels within the bitumen following oxidation results in an increase in the polarity of the by-products, hardening of the bulk phase, an increase in viscosity and loss of cohesion/adhesion within the asphalt pavement. [5] Small aggregates are lost from the surface as a result of the loss of cohesion between the bitumen and aggregates. This failure is termed 'fretting' and can lead to the formation of cracks and potholes in the road surface. 
These failures make the road surface unsafe and uncomfortable for road users with expensive re-surfacing required to make the road safe again.

Chemical oxidation of the bitumen occurs initially during the transportation of the bitumen to the road site from the supplier, during which the bitumen is heated and exposed to air. This short term ageing is a well-known phenomenon and can be replicated by using the standardised rolling thin film oven (RTFO) test. [6]

Once the road has been laid the bitumen cools and the ageing slows. The ageing that the bitumen experiences when the road is in service is termed long-term ageing [3] and has a complex mechanism due to the higher number of factors to which the asphalt is exposed. There are standardised tests that aim to replicate the in-service ageing of the raw bitumen. [7] These tests include the rotating cylinder ageing test (RCAT) [8] and the pressure ageing vessel (PAV). [9] However, at present, reliable tests that replicate the ageing of the actual asphalt pavement samples have not been established because of the unpredictability and the variability in environmental conditions that the asphalt may experience in service. These variable factors include: temperature-cycling, UV exposure, rainfall and both traffic loading and intensity.

It has been identified that the effect of UV radiation is a contributing factor to the road surface deterioration and this has been thoroughly investigated in recent years. $[10,11,12]$ Previously published work has shown the correlation between the viscosity of raw bitumen and UV exposure. This has been published by Wu et. al, [13] who compared the effects of the PAV, UV and natural ageing on raw bitumen. It was reported that there was an increase in stiffness of the bitumen after UV ageing and natural exposure ageing and that this effect is dependent upon the bitumen film thickness. Other results leading to similar conclusions have also been published in the literature. [14,15]

These changes in physical properties of the raw bitumen have been seen to correlate with oxidation of the bitumen. This oxidation can be monitored using ATR-infrared spectroscopy. $[16,17,18,19]$

Many studies have reported oxidation product absorbance bands arising in the spectra from aged raw bitumen. [20] These functional groups include carbonyl, carboxyl and sulphoxide groups and these give rise to absorbance bands at approximately: 1760-1615, 1320-1000 and $1000-900 \mathrm{~cm}^{-1}$, respectively. [21]

FTIR-ATR spectroscopy works well to analyse raw bitumen as good contact can be achieved between the sample and the ATR crystal. However, it is difficult to obtain sufficient contact between an asphalt road surface and an ATR crystal as the asphalt forms a hard uneven solid surface once cooled. Therefore a non-contact infra-red technique is more suitable in order to analyse and monitor the oxidation of the bitumen after it has been laid as an asphalt road surface.

The research described in this paper investigates the feasibility of monitoring the oxidation of bitumen in asphalt samples using diffuse reflectance infrared Fourier transform (DRIFT) spectroscopy.

The following questions will be addressed;

(i) Can evidence be obtained for the formation of functional groups produced from the oxidation of raw bitumen that has been aged both artificially and naturally?

(ii) Can these peaks be seen using DRIFT spectroscopy?

(iii) Can the absorbance bands corresponding to bitumen, filler and aggregates be assigned in the DRIFT spectra of a sample of asphalt? 
(iv) Can the oxidation functional group absorbance bands be monitored by DRIFT spectroscopy in a sample of asphalt as it is aged both artificially and naturally?

\section{Methodology}

A UV chamber, which contained 8 Sylvania UV lamps that emit UV light at $368 \mathrm{~nm}$ was used for the artificial ageing experiments. The chamber was held at $60{ }^{\circ} \mathrm{C}$ for the duration of the experiments.

The infrared spectroscopic analysis on all samples was carried out using an ExoScan 4100 hand-held spectrometer with a diffuse reflectance detector attachment. The reflectance spectra reported are an average of 64 scans with an $8 \mathrm{~cm}^{-1}$ resolution.

A systematic approach was employed to monitor the oxidation of raw bitumen samples as they are aged artificially using the UV chamber and naturally with exposure to natural UV light. This allowed for the oxidation product absorbance bands to be identified. Following this, asphalt samples were produced that represent a "real" asphalt road surface i.e. samples that were produced using identical methods to those used to create road surfaces. These samples were aged artificially and naturally in the same manner as the raw bitumen.

\section{Bitumen sample preparation and ageing}

A sample of 40/60 penetration-grade bitumen [3] was used for these ageing experiments. The penetration grade of bitumen is a measure of its consistency and is determined using a standard penetration point test. [22] The bitumen $(150 \mathrm{~g})$ was poured into four $100 \times 40 \mathrm{~mm}$ aluminium containers and placed into the UV chamber. One sample was removed at weekly time intervals and reflectance spectra were taken from the surface. This procedure was repeated for three weeks. One sample of bitumen was placed into the chamber and was covered so that it was not exposed to the UV light. This sample was removed after three weeks and spectra were obtained from its surface. Three further bitumen samples were prepared in the same way and were placed onto the roof of the Transport Research Laboratory headquarters at Crowthorne House, Crowthorne, UK. These samples were exposed to natural conditions of UV exposure, rainfall and temperature fluctuations; these parameters were monitored by a weather station.

\section{Asphalt slab preparation and ageing}

Samples of United Asphalt, Stone Mastic Asphalt (SMA) [23] were produced for this study. These samples contained 100/150 penetration grade binder [24] with hard stone aggregates. These aggregates are a combination of stones which include limestone and granite. Limestone is principally composed of calcium carbonate while granite consists mainly of a mixture of quartz (silicon dioxide) and feldspars which contain silica and alumina alongside other minerals. [25] The asphalt slabs were $200 \times 200 \times 50 \mathrm{~mm}$ and ca. $4 \mathrm{~kg}$ in weight and they comply with materials specification EN 13108. [26] These blocks have a maximum aggregate size of $10 \mathrm{~mm}$ and a binder content of $6 \%$.

DRIFT spectra were taken at specific coordinates on the surface of one of these asphalt samples. The mapped sample was then placed into the UV chamber and at weekly intervals the slab was removed and DRIFT spectra were taken at the same surface coordinates.

A second unaged asphalt sample was mapped in the same way as above and then placed onto the roof of Crowthorne House. This sample was removed from the roof at weekly time 
intervals and the same co-ordinates were used to record DRIFT spectra from the surface. This process was repeated for 4 weeks.

\section{Results and Discussion}

Reflectance spectra have a very different appearance to ATR spectra as a result of the difference in detection method. Many bands in DRIFT spectra show a poor signal-to-noise ratio. In addition to diffuse reflectance of the light, specular reflectance may occur from the surface being irradiated. If the sample is shiny this leads to an increase in the amount of specular reflectance which occurs when light hits a sample and is reflected from the surface at an angle that is equal to the incident angle. This leads to distortion of absorbance bands in the reflectance spectra and the observed spectrum will be a sum of the diffuse and specular reflectance. First derivative peaks are observed in specular reflectance spectra when there is a change in absorbance due to a change in refractive index as the IR beam moves through a range of wavelengths. [27] In the case of the carbonyl absorbance observed in Figure 1 there is a maximum reflectance at a high wavenumber and a minimum reflectance at a lower wavenumber, 1782 and $1696 \mathrm{~cm}^{-1}$, respectively. The central position of this first derivative absorbance band is at approximately $1750 \mathrm{~cm}^{-1}$ which is the expected location of a carbonyl absorbance band. The central position is where the peak crosses from a positive to negative absorbance. In interpreting these spectra it should be noted that the vertical axis shows reflectivity and lower values of reflectivity indicate a higher absorbance.

\section{Bitumen UV ageing results}

The DRIFT spectra shown in Figure 1 were collected at weekly intervals from the surface of the raw bitumen samples after they had been aged in the UV chamber for 3 weeks.

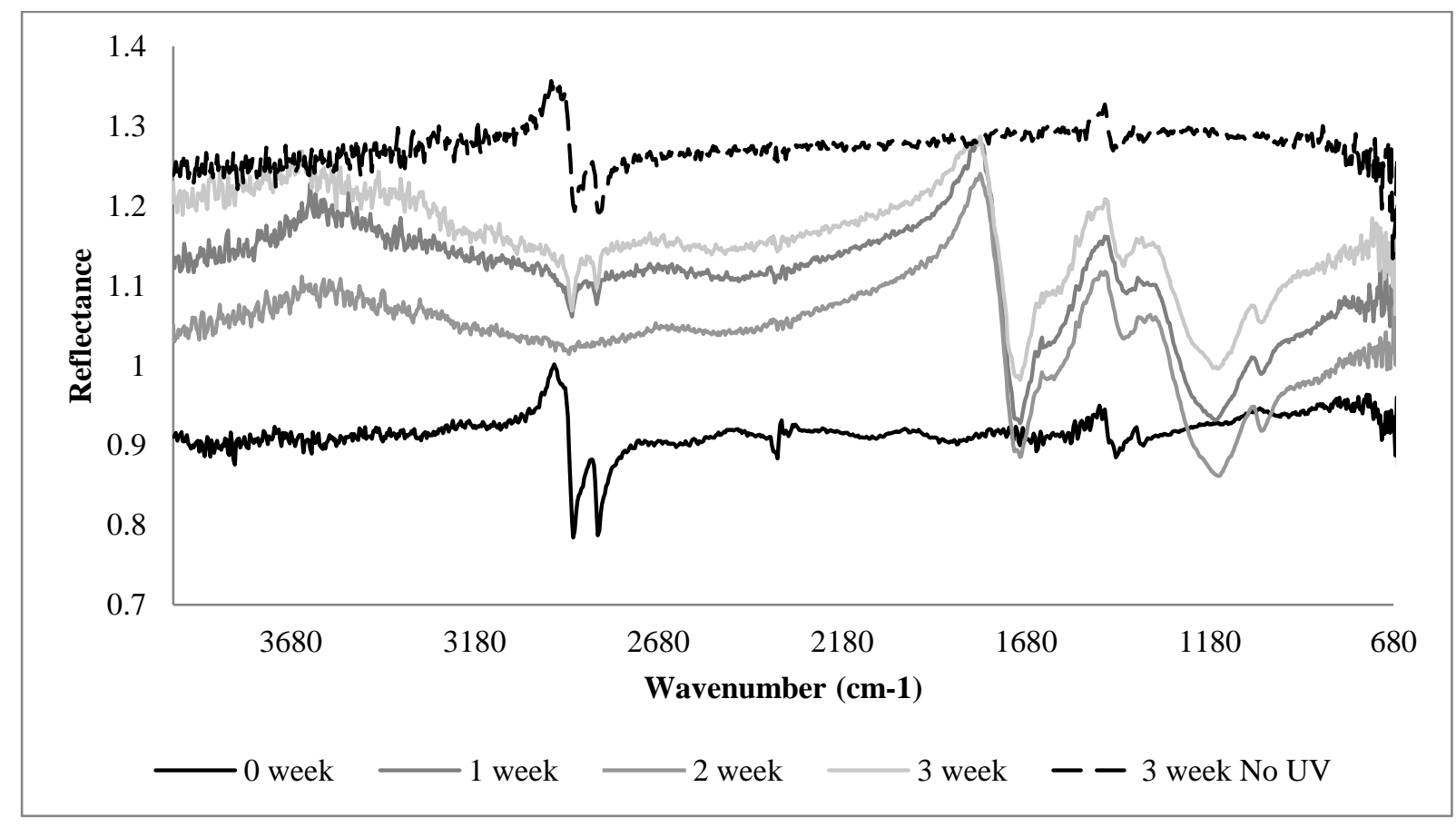

Figure 1 DRIFT spectra from the surface of raw bitumen samples that have been aged in a UV chamber for 3 weeks

There is a large first derivative feature present in the samples that have been aged with the UV light. This feature is a first derivative of the carbonyl absorbance at approximately $1750 \mathrm{~cm}^{-1}$. Table 1 lists the observed IR bands and shows the presence of a number of 
different functional groups that suggest that oxidation of the bitumen has occurred on the surface of the UV aged samples.

Table 1 Outline of the absorbance band wavenumber positions and the bond assignments from the reflectance spectra in Figure 1

\begin{tabular}{|l|l|}
\hline Absorbance Band $\left(\mathbf{c m}^{-\mathbf{1}}\right)$ & Bond assignment \\
\hline 2900,2840 & C-H stretch \\
\hline 1750 (centre of $1^{\text {st }}$ derivative peak) & C=O stretch \\
\hline 1192 & C-O stretch \\
\hline 1047 & S=O stretch \\
\hline
\end{tabular}

Several studies have demonstrated the ability to monitor and quantify the degree of oxidation in raw bitumen samples subjected to ageing by measuring the peak area of a number of different absorbance bands and calculating indices using the ratios of the peak areas. [28, 29] The Beer-Lambert law states that absorbance is directly proportional to concentration. This means that theoretically the intensity of an absorbance band of a specific functional group can be related to the concentration of the group in the sample. This theory can be applied reliably to ATR spectra however when analysing DRIFT spectra, care needs to be taken when measuring peak areas and using these values for quantification. As a result of overlapping absorbance bands and light scattering from the surface it is difficult to reliably quantify absorbance band areas in DRIFT spectra. As seen above in Figure 1 there is a first derivative absorbance band arising between the wavenumbers $1980-1460 \mathrm{~cm}^{-1}$. As a result of the first derivative nature of this peak the area cannot be used to reliably quantify and increase in concentration of the carbonyl group as the area of a first derivative peak should, in theory, equal 0 . For this report the first derivative peaks have been quantified by measuring half of the first derivative peak. In this report absorbance band areas have been quantified as an arbitrary measurement to determine the presence of a general trend.

Figure 2 outlines a number of absorbance bands from Figure 1 and their measured area. The results show that there is an increase in the carbonyl peak area between wavenumbers 1755$1636 \mathrm{~cm}^{-1}$ and also an increase in absorbance band area between the wavenumbers 1338-969 $\mathrm{cm}^{-1}$. This area corresponds to both carboxylic and sulphoxide bonds vibrating. Figure 2 also shows a decrease in the absorbance band that corresponds to $\mathrm{C}-\mathrm{H}$ bonds vibrating (2952-2773 $\mathrm{cm}^{-1}$ ). After more than 1 week of UV exposure there is little change observed in these peak areas and this is represented by a plateau in Figure 2. 


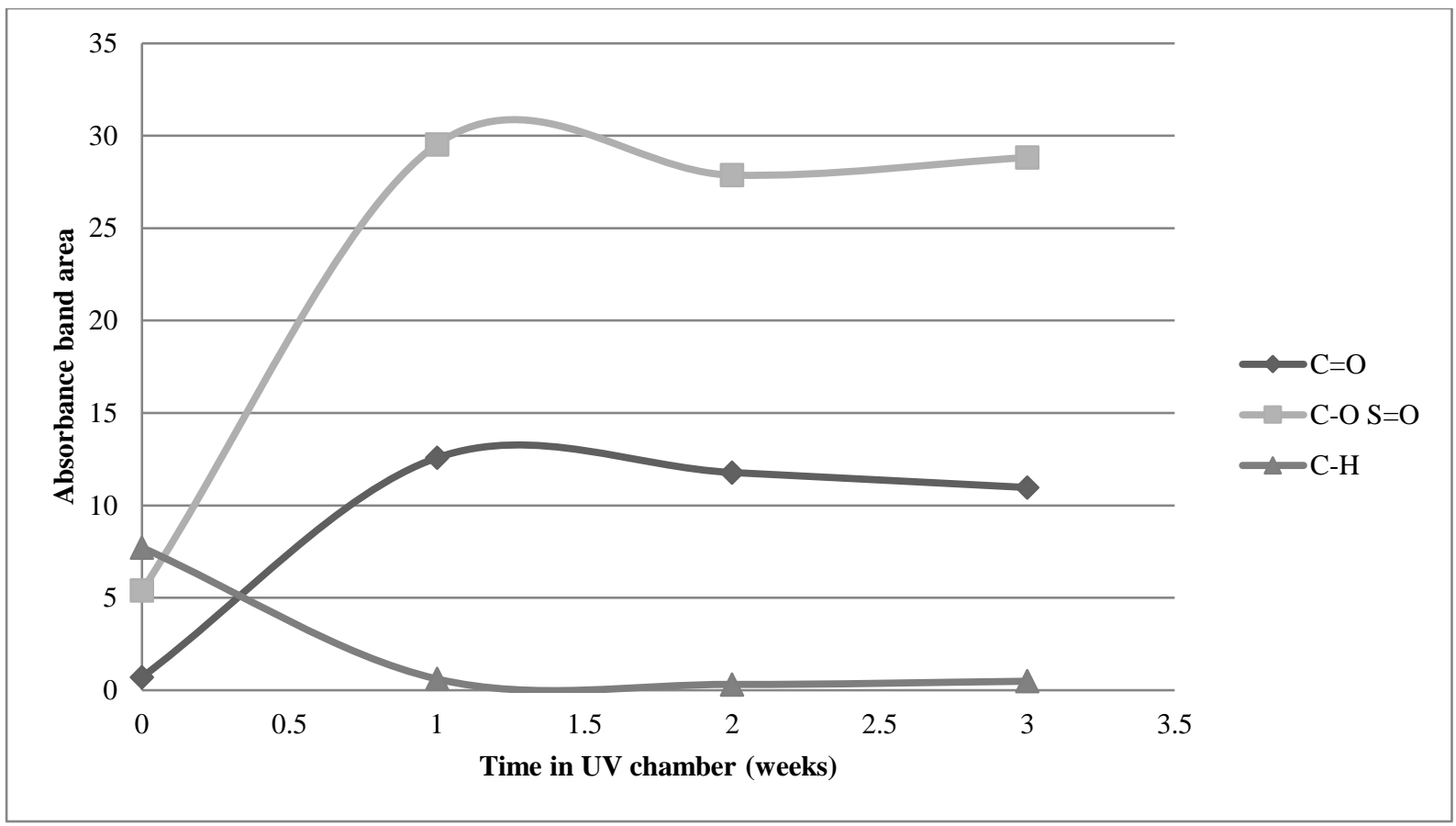

Figure 2 Chart to show the functional group absorbance band areas from the DRIFT spectra from the surface of the UV aged bitumen, $C=O\left(1755-1636 \mathrm{~cm}^{-1}\right), C-O\left(1338-969 \mathrm{~cm}^{-1}\right)$ and $\mathrm{C}-\mathrm{H}\left(2952-2773 \mathrm{~cm}^{-1}\right)$

\section{Naturally aged bitumen results}

The DRIFT spectra in Figure 3 were collected from the surface of the raw bitumen samples that had been aged naturally on the roof of Crowthorne House, UK.

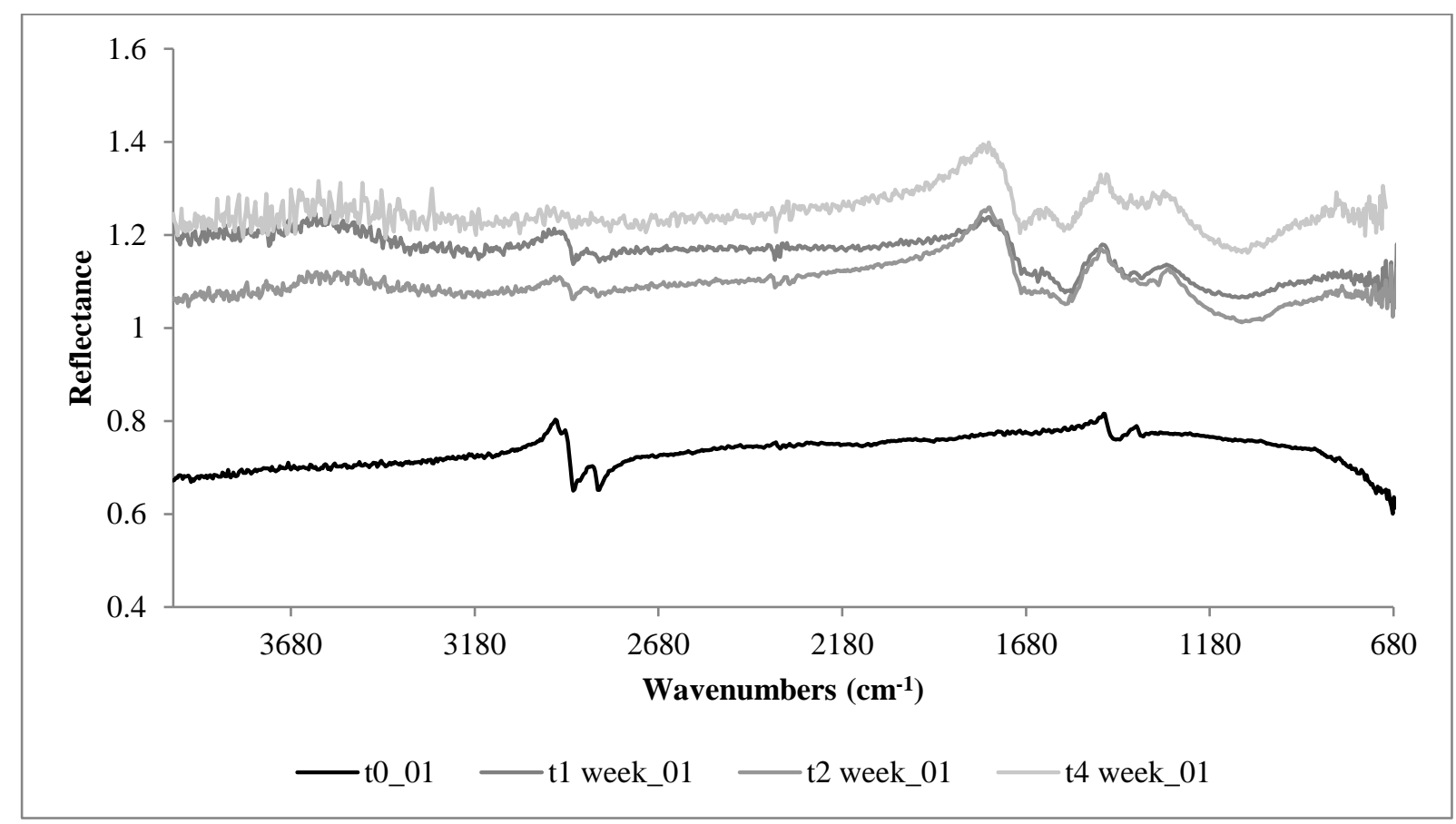

Figure 3 DRIFT spectra from the surface of raw bitumen samples that have been aged on the roof of Crowthorne House, UK for a period of 4 weeks

In the unaged raw bitumen spectrum (t0_01) the $\mathrm{C}-\mathrm{H}$ bending and stretching bands are the only features observed. However, after 1 week of natural ageing there is a large carbonyl absorbance band arising in the following spectra. A broad absorbance band can also be seen 
at $c a .1118 \mathrm{~cm}^{-1}$. Again, the superposition of diffuse and specular reflectance spectra make interpretation of these spectra somewhat complex. A summary of the bands and their assignments can be found below in Table 2 .

Table 2 Outline of absorbance bands in the reflectance spectra from Figure 3 and their bond assignments

\begin{tabular}{|l|l|}
\hline Absorbance Band $\mathbf{c m}^{-\mathbf{1}}$ ) & Bond assignment \\
\hline 2911,2840 & C-H stretch \\
\hline 1767 & $\mathrm{C}=\mathrm{O}$ stretch \\
\hline 1468,1379 & $\mathrm{CH}_{2}$ bend \\
\hline 1118 & $\mathrm{C}-\mathrm{O}$ stretch (broad) \\
\hline
\end{tabular}

There is evidence of oxidation on the surface of raw bitumen samples during the 4 weeks of natural exposure. The measured UV exposure that the sample experienced is shown in Figure 4.

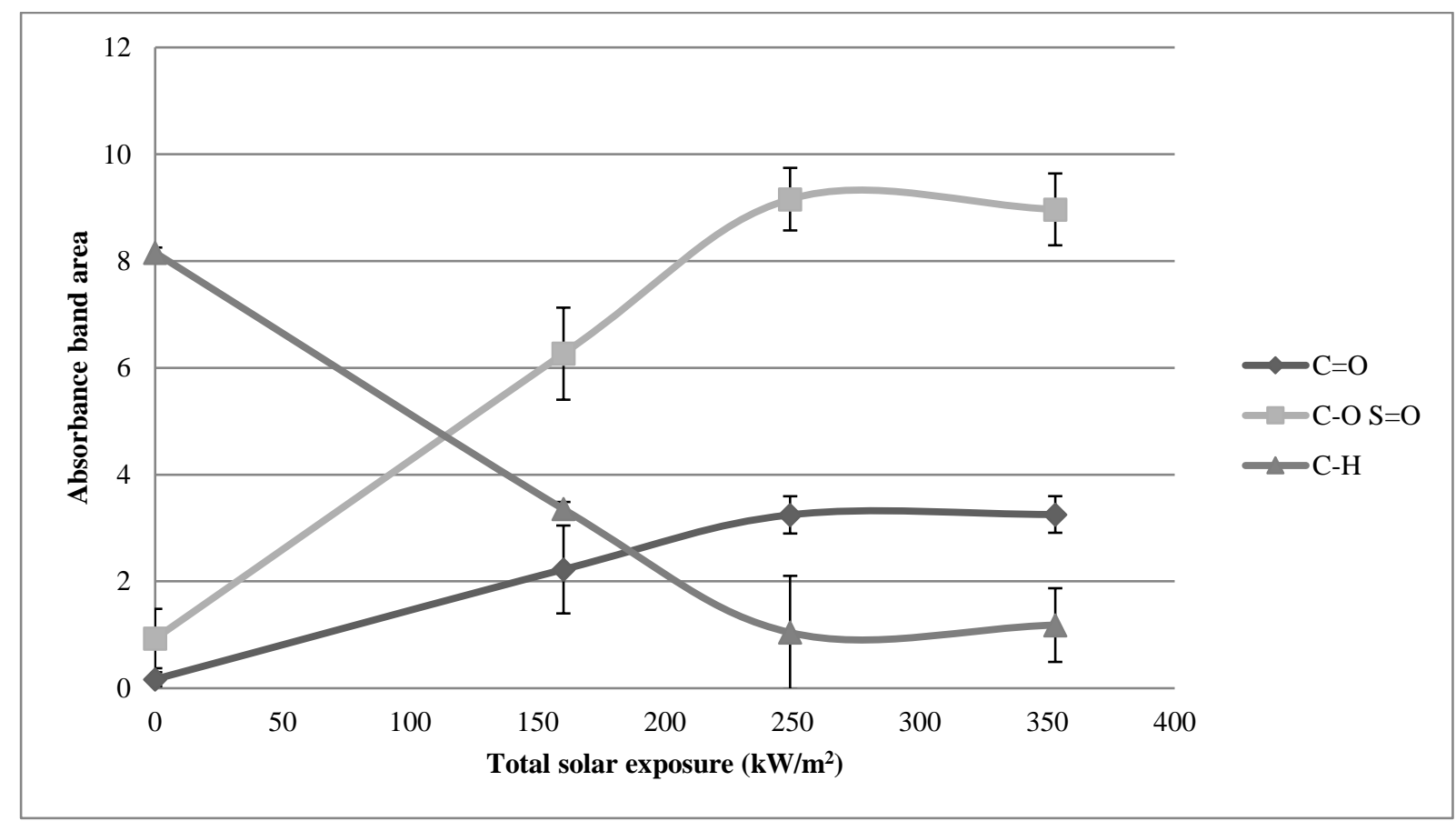

Figure 4 Average absorbance band areas from the DRIFT spectra from the surface of the asphalt slab that has been aged for 0-4 weeks in the UV chamber. $C=O\left(1755-1636 \mathrm{~cm}^{-1}\right), C-O$ and $S=O\left(1338-969 \mathrm{~cm}^{-1}\right)$ and $C-H\left(2952-2773 \mathrm{~cm}^{-}\right.$ 1)

The results in Figure 4 show that as the bitumen is exposed to solar exposure there is an increase in carbonyl, carboxylic and sulphoxide absorbance band areas. This is seen alongside a decrease in C-H absorbance band area between the wavenumbers $2952-2773 \mathrm{~cm}^{-}$ ${ }^{1}$. This trend occurs until a plateau is reached between 2-4 weeks. This suggests that there is a limited amount of oxidation sites possible within the structure of the bitumen.

\section{UV Aged Asphalt slab results}

The reflectance spectra shown in Figure 5 were recorded from the surface of the asphalt slab that had been aged in the UV chamber for 4 weeks. 


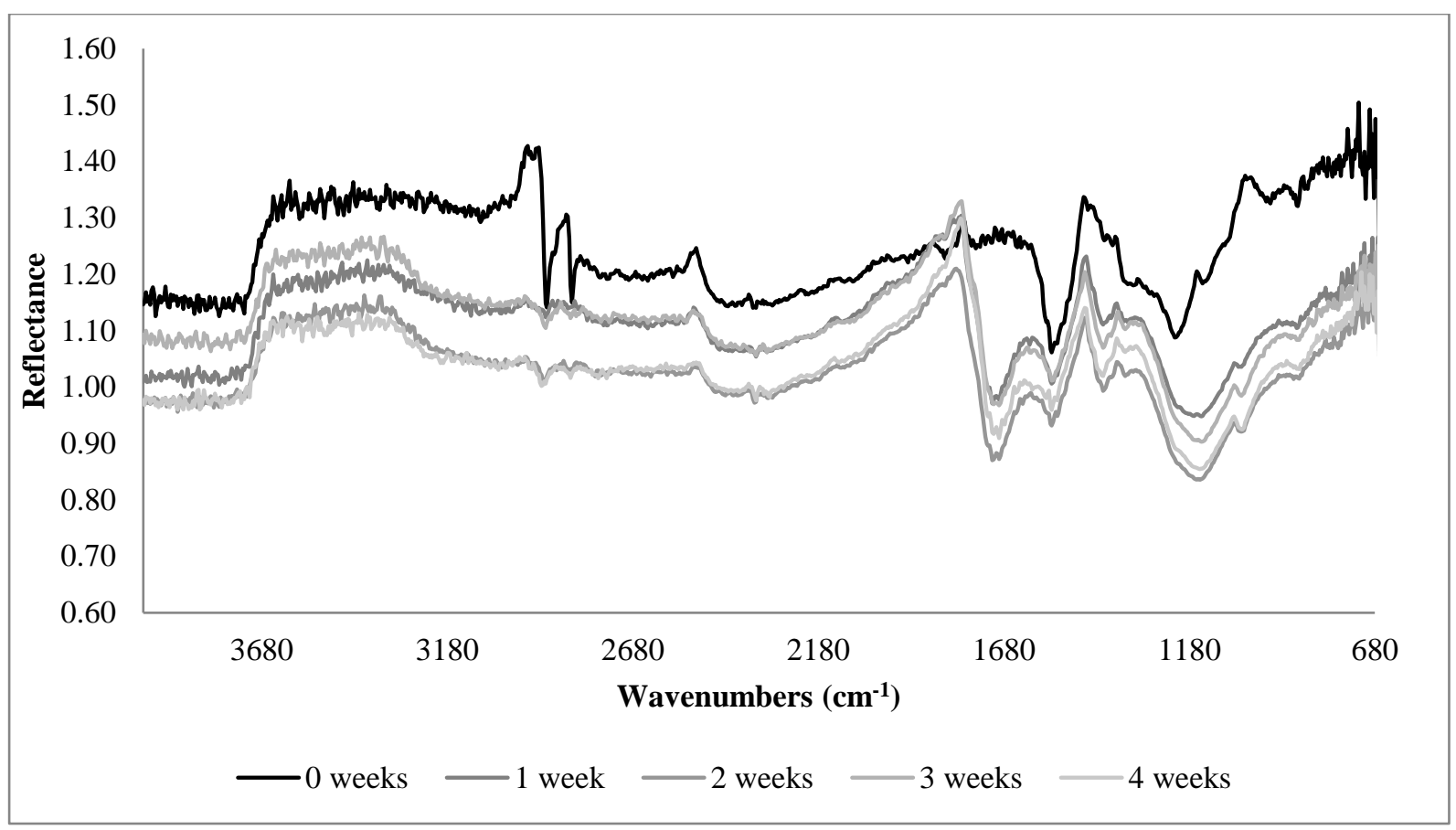

Figure 5 DRIFT spectra from the surface of an asphalt slab aged in the UV chamber for 4 weeks

There are some similarities between the absorbance bands in the spectra from the raw bitumen and the asphalt. The $\mathrm{C}-\mathrm{H}$ absorbance bands are very clear in the unaged sample. Absorbance bands that correspond to vibrations of the carbonate ion in calcium carbonate (resulting from the limestone filler) are also observed. These are outlined in Table 3.

Table 3 Absorbance bands from the reflectance spectra of the UV aged asphalt slab shown in Figure 5 and their bond assignments

\begin{tabular}{|l|l|}
\hline Absorbance Band $\left(\mathbf{c m}^{-1}\right)$ & Bond assignment \\
\hline 2900,2840 & $\mathrm{C}-\mathrm{H}$ (stretch) \\
\hline 2510 & $\mathrm{CO}_{3}{ }^{2-}$ (overtone) \\
\hline 1750 (centre of $1^{\text {st }}$ derivative peak) & $\mathrm{C}=\mathrm{O}$ (stretch) \\
\hline 1460 & $\begin{array}{l}\mathrm{CO}_{3}{ }^{2-} \quad \text { asymmetric } \\
\text { stretch) }\end{array}$ \\
\hline 1220 & $\mathrm{C}-\mathrm{O}$ (stretch) \\
\hline 1192 & $\mathrm{Si}-\mathrm{O}$ (stretch) \\
\hline 1047 & $\mathrm{~S}=\mathrm{O}$ (stretch) \\
\hline 887 & $\begin{array}{l}\mathrm{CO}_{3}{ }^{2-} \text { (out of plane } \\
\text { bend) }\end{array}$ \\
\hline
\end{tabular}

The evolution of the first derivative wave feature between 1920 and $1610 \mathrm{~cm}^{-1}$ is observed as seen in the UV-aged raw bitumen (see Figure 1). This feature is seen after 1 week in the UV chamber and does not change shape after this time period. It shows overlap with the carbonate $\mathrm{CO}_{3}{ }^{2-}$ asymmetric stretch absorbance band at $1460 \mathrm{~cm}^{-1}$ giving a broad appearance in the aged sample spectra. 
It is very important in this research to be able to differentiate between the carbonyl absorbance from the oxidised bitumen, expected between $1710-1665 \mathrm{~cm}^{-1}$ wavenumbers, and the $\mathrm{CO}_{3}{ }^{2-}$ combination mode which is expected at approximately $1790 \mathrm{~cm}^{-1}$. [30, 31] Calcium carbonate also shows absorbance bands resulting from $\mathrm{CO}_{3}{ }^{2-}$ overtone and asymmetric stretch vibrations at approximately 2510 and $1460 \mathrm{~cm}^{-1}$, respectively. [30, 31,32]

DRIFT spectra were taken from 27 coordinates on the surface of the asphalt slab at each time point. The carbonyl absorbance band (1826-1763 $\mathrm{cm}^{-1}$ ) area was measured for all spectra and the average at each time interval has been plotted in Figure 6.

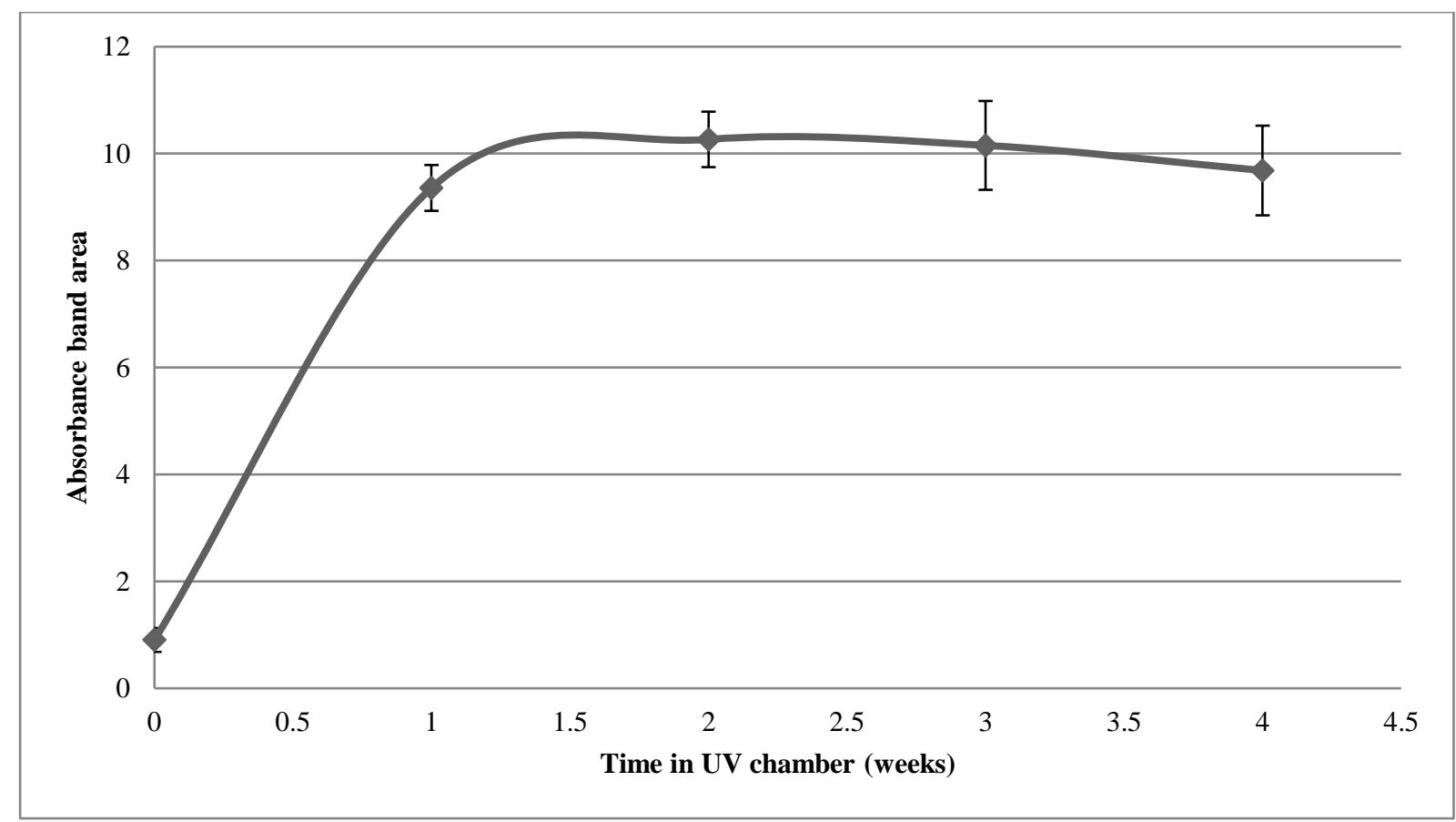

Figure 6 Average integrated carbonyl peak area between wavenumbers $1755-1636 \mathrm{~cm}^{-1}$ from 27 DRIFT spectra collected from the surface of the UV aged asphalt slab. Error bars are the $95 \%$ confidence intervals for the data set.

It is clear that there is an increase in the carbonyl peak area as the asphalt is aged in the UV chamber. There is a large increase in average absorbance band area between 0 and 1 weeks of UV ageing and then a reduction in this increase in absorbance band area as the ageing progresses. This corresponds to the results seen in Figure 5. This indicates that most of the unsaturated sites within the surface layers of the bitumen are becoming oxidised within the first week of artificial UV exposure.

\section{Naturally Aged Asphalt Slab Results}

In Figure 7 is shown the DRIFT spectra from the surface of the asphalt sample that was aged on the roof of Crowthorne House. 


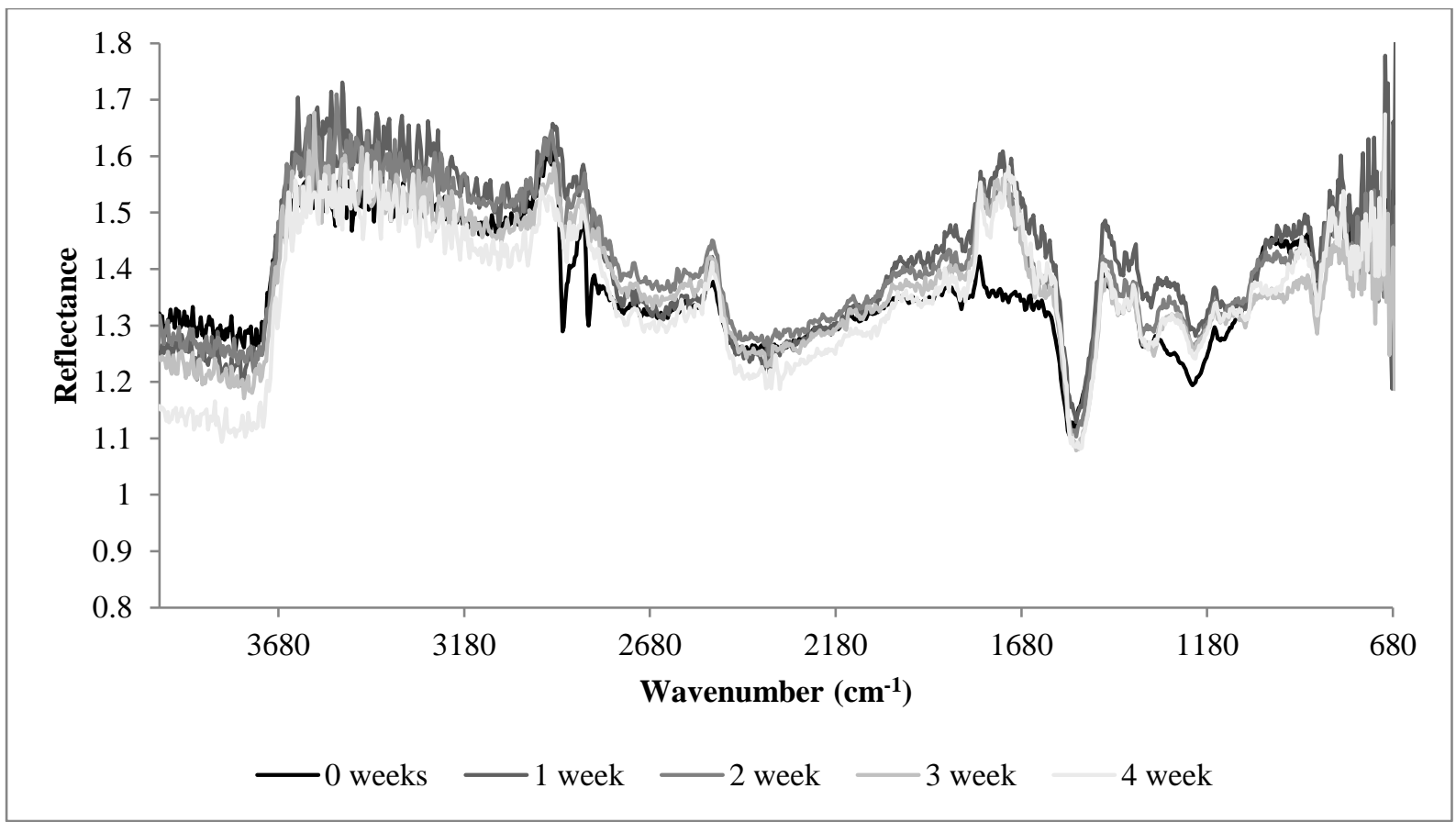

Figure 7 DRIFT spectra of the surface of the asphalt sample that has been naturally aged on the roof of Crowthorne House for a period of 4 weeks

The spectra shown in Figure 7 show a normal absorbance band arising between wavenumbers 1760-1645 $\mathrm{cm}^{-1}$. This correlates to the carbonyl absorbance band. This peak is not a first derivative unlike the corresponding carbonyl bands shown in Figure 1 and Figure 5. This is due to a lower reflectivity of the naturally-aged asphalt samples compared to the UV aged samples. As the asphalt is aged in the UV chamber it remains very shiny and black as a result of the high temperature within the UV chamber. This means that the DRIFT spectra are a combination of specular and diffuse reflectance leading to derivative type peaks. However when the asphalt is exposed to natural ageing conditions, the temperature is reduced and cycled and the UV exposure is less intense. The bitumen turns a dull grey colour as a result of the changing conditions. This means that the DRIFT spectra are dominantly diffuse reflectance and the spectra are less complex. Table 4 outlines the absorbance bands from Figure 7.

Table 4 Absorbance bands and their bond assignments measured in the DRIFT spectra from the surface of the naturally aged asphalt shown in Figure 7.

\begin{tabular}{|l|l|}
\hline Absorbance Band $\left.\mathbf{( c m}^{-1}\right)$ & Bond assignment \\
\hline 2844,2915 & $\mathrm{C}-\mathrm{H}$ (stretch) \\
\hline 2512 & $\mathrm{CO}_{3}{ }^{2-}$ (overtone) \\
\hline 1730 & $\mathrm{C}=\mathrm{O}$ (stretch) \\
\hline 1532 & $\begin{array}{l}\mathrm{CO}_{3}{ }^{2-} \quad \text { asymmetric } \\
\text { stretch) }\end{array}$ \\
\hline 1234 & $\mathrm{C}-\mathrm{O}$ (stretch) \\
\hline 1155 & $\mathrm{~S}=\mathrm{O}$ (stretch) \\
\hline
\end{tabular}


The carbonyl peak at $1730 \mathrm{~cm}^{-1}$ appears after 1 week of natural ageing. The absorbance band shows no significant shape change in area between 1 and 4 weeks. The absorbance band areas can be seen in Table 5 .

Table 5 Outline of the solar exposure that the asphalt slab has been exposed to during the 4 week natural ageing period and the carbonyl absorbance band area from the reflectance spectra that can be found in Figure 7

\begin{tabular}{|l|l|l|l|}
\hline $\begin{array}{l}\text { Time } \\
\text { naturally } \\
\text { aged } \\
\text { (weeks) }\end{array}$ & $\begin{array}{l}\text { Date spectra were } \\
\text { collected } \\
\text { sample }\end{array}$ & $\begin{array}{l}\text { Solar UV } \\
\text { exposure total } \\
\left(\mathbf{k W} / \mathbf{m}^{2}\right)\end{array}$ & $\begin{array}{l}\text { Carbonyl peak } \\
\text { area }\end{array}$ \\
\hline $\mathbf{0}$ & 19.04 .17 & 0 & 0.652 \\
\hline $\mathbf{1}$ & 26.04 .17 & 93.246 & 6.895 \\
\hline $\mathbf{2}$ & 3.05 .17 & 160.148 & 5.651 \\
\hline $\mathbf{3}$ & 10.05 .17 & 249.133 & 5.350 \\
\hline $\mathbf{4}$ & 17.05 .17 & 331.701 & 8.819 \\
\hline
\end{tabular}

A sharp absorbance band at $1798 \mathrm{~cm}^{-1}$ can be observed on the shoulder of the $\mathrm{C}=\mathrm{O}$ stretch centered at $1730 \mathrm{~cm}^{-1}$. This correlates to a carbonate combination absorbance band [30] which is seen clearly in the initial spectrum before any natural exposure ( 0 weeks). This peak is not observed in the spectra from the UV aged asphalt, shown in Figure 5, as it is masked by the overlap of the large first derivative absorbance band arising between wavenumbers 1971$1590 \mathrm{~cm}^{-1}$ after 1 week of UV ageing of the asphalt slab.

\section{Conclusions}

The results obtained in this work lead to the following conclusions:

(i) The oxidation functional group absorbance bands are clearly observed in the raw bitumen that has been aged both artificially and naturally. These absorbance bands correspond to the $\mathrm{C}=\mathrm{O}, \mathrm{C}-\mathrm{O}$ and sulphoxide $\mathrm{S}=\mathrm{O}$ bond stretches.

(ii) These peaks are identifiable in the DRIFT spectra of raw bitumen. There are some variations to the appearance of the carbonyl absorbance band due to a number of physical characteristics of the surface being analysed. This peak presents as a first derivative (1972-1679 $\mathrm{cm}^{-1}$ ) when the sample is shiny, for example raw bitumen and UV aged asphalt. This first derivative is a result of a mixture of specular and diffuse reflectance of the IR radiation.

(iii) The absorbance bands present in the spectra from the asphalt have been assigned to bitumen, calcium carbonate filler and the aggregates. The carbonyl absorbance band $\left(1730 \mathrm{~cm}^{-1}\right)$ can be distinguished from the calcium carbonate $\mathrm{CO}_{3}{ }^{2-}$ overtone absorbance band $\left(1789 \mathrm{~cm}^{-1}\right)$ by careful interpretation of the spectra.

(iv) The carbonyl absorbance band can be monitored as the asphalt samples are aged artificially and naturally. This peak presents as a first derivative in the spectra from the UV aged asphalt. However the spectra from the naturally aged asphalt show the evolution of a 'normal' carbonyl absorbance band arising in the DRIFT spectra. This can be seen after only one week of natural exposure.

In conclusion this research suggests that the oxidation of bitumen within an asphalt road surface could be monitored across the mid-IR range. From this research it is concluded that the oxidation of bitumen as a binder in asphalt samples can be monitored using non-contact 
diffuse reflectance IR spectroscopy. It is also clear that by observing these oxidation reactions the first stages of degradation of the road surface are also being monitored. In principle DRIFT could be a useful tool in assessing the early stages of degradation of a road pavement.

\section{Acknowledgements}

We acknowledge the funding from Highways England and Transport Research Laboratory for a PhD studentship for H.B. We also thank Donald Burton of Highways England and Dr Helen Viner from the Transport Research Laboratory for useful technical discussions. We also acknowledge Andrew Hannay and John Prime at the Transport Research Laboratory for constructing the UV chamber and the asphalt samples used in this project.

\section{References}

1 Department for Transport Statistical release, Road Conditions in England 2014, https://www.gov.uk/government/uploads/system/uploads/attachment_data/file/409193/road-conditions-inengland-2014.pdf ACCESSED 01.08.2017 14:59

${ }^{2}$ The Asphalt Institute, Introduction to Asphalt, Manual Series No. 5, $8^{\text {th }}$ Ed, USA, 1984

${ }^{3}$ J. Reed and D. Whiteoak, The Shell Bitumen Handbook, $5^{\text {th }}$ Edition, Thomas Telford Publishing, London, 2003, ISBN: 0-7277-3220-X

4 The Asphalt Institute and Eurobitume, The Bitumen Industry- A Global Perspective, Production, chemistry, use, specification and occupational exposure, $3^{\text {rd }}$ Ed, USA, 2015, ISBN: 978-1-934154-73-1

5 S. Weigel and D. Stephan, Relationships between the chemistry and the physical properties of bitumen, Road Mater. Pavement, (2017), DOI:10.1080/14680629.2017.1338189

6 European Standard EN 12607-1, 1999, Bitumen and bituminous binders- Determination of the resistance to hardening under the influence of heat and air-Part 1: RTFOT method

7 A. Verhasselt, Short and Long-Term Ageing of Bitumen and Bituminous Binders-Simulation with RCAT Method, $6^{\text {th }}$ RILEM Symposium, PTEBM'03, Zurich, 2003

${ }^{8}$ British Standard EN 15323:2007, Bitumen and bituminous binders-Accelerated long-term ageing/ conditioning by the rotating cylinder method (RCAT)

9 British Standard EN 14769:2012, Bitumen and bituminous binders -Accelerated long-term Ageing conditioning by a Pressure Ageing Vessel (PAV)

${ }^{10}$ M. Bocci and G. Cerni, The ultraviolet radiation in short -term and long- term ageing of bitumen, Pric. $2^{\text {nd }}$ Eurbitumen and Eurobitume Congress, Session 1: Performance testing and Specifications for Bitumen and Mixtures, Barcelona, (2000), 49-58

11 A. Montepara, E. Santagata and G. Tosi, Photochemical degradation of pure bitumen by UV radiation, Proc. $1^{\text {st }}$ Eurbitumen and Eurobitume Congress, Strasbourg, E\&E, 5, (1996), 133

${ }^{12} \mathrm{~S}$. Wu, L. Pang, G. Liu, and J. Zhu, Laboratory Study on Ultraviolet Radiation Ageing of Bitumen, J. Mater. Civil Eng., 22(8), (2010), 767-772

${ }^{13} \mathrm{~S}$. Wu, L. Pang, L. Mo, J. Qiu, G. Zhu and Y. Xiao, UV and thermal ageing of pure bitumen- comparison between laboratory simulation and natural exposure Ageing, Road Mater. Pavement, EATA, (2008), 103-113

${ }^{14}$ V.F.C. Lins, M.F.A.S. Arauji, M.I. Yoshida, V.P. Ferraz, D.M. Andrada and F.S Lameiras, Photodegradation of hot-mix asphalt, Fuel, 87, (2008), 3254-3261

${ }^{15}$ M. F. A. S. Araujo, V. F. C. Lins, V. M. D. Pasa and L. F. M. Leite, Weathering aging of modified asphalt binders, Fuel Process Technol., 115, (2013), 19-25

${ }^{16}$ X. Lu and U. Isacsson, Effect of ageing on bitumen chemistry and rheology, Const. Build. Mater., 16, (2002), $15-22$

${ }^{17}$ X. A. Vargas, N. Afanasjeva, M. Álverez, P. H. Marchal and L. Choplin, Asphalt rheology evolution through thermo-oxidation (ageing) in a rheo-reactor, Fuel, 87, (2008), 3018-3023

${ }^{18}$ S. Saoula, K. Soudani, S. Haddiadi, M. E. Munoz and A. Santamaria, Analysis of the Rheological Behaviours of Ageing Bitumen and Predicting the Risk of Permanent Deformation of Asphalt, MSA, 4, (2013), 312-318

19 X. Li, A. Zofka, M. Marasteanu and T. R. Clyde, Evaluation of field ageing effects on asphalt binder properties, Road Mater., Pavement, (2006), 57-73

${ }^{20}$ M. R. Nivitha, E. Prasad and J. M. Krishnan, Ageing in modified bitumen using FTIR Spectroscopy, Int., J., Pav., Eng., 2015, DOI [http://dx.doi.org/10.1080/10298436.2015.1007230] 
${ }^{21}$ B. Stewart, W. O. George, P. S. McIntyre, Modern infrared spectroscopy, ACOL, New York, 1996, ISBN:0471959162

${ }^{22}$ British Standard EN 1426:2015, Bitumen and bituminous binders- Determination of needle penetration

${ }^{23}$ R. Hainin, W. F. Reshi and H. Niroumand, The importance of Stone Mastic Asphalt in Construction, EJGE, 17, (2012)

${ }^{24}$ Bitumen 100/150 Penetration Paving Bitumen Grade, Product Data Sheet, 2013

http://bitumina.co.uk/pdf/BITUMEN_100-150_PEN_EC.pdf ACCESSED 11.08.17 09:53

25 Mineral Education Coalition, Minerals Database, Crushed Stone https://mineralseducationcoalition.org/minerals-database/crushed-stone/ ACCESSED 02.08.2017 10:31

${ }^{26}$ British Standard EN 13108-1:2006, Bituminous mixtures, Asphalt Concrete

27 R. Spragg, Perkin Elmer Technical Note, Reflection Measurements in IR Spectroscopy. www.perkinelmer.com/CMSResources/Images/44-153348TCH_reflection-Measurements.pdf ACCESSED 02.08.2017 10:34

${ }^{28}$ S. Huang, J. F. Branthaver, R. E. Robertson, The influence of aggregate on moisture susceptibility in terms of bitumen-aggregate interactions, $6^{\text {th }}$ RILEM Symposium, PTEBM'03, Zurich, (2003)

${ }^{29} \mathrm{~J}$. N. Israelachvili, Intermolecular and surface forces, $3^{\text {rd }}$ ed., Elsevier, (2011), eBook ISBN: 9780123919335

${ }^{30}$ J. Godleman, M. Almond and W. Matthews, J. Archaeol. Sci: Reports, 7, (2016), 195-204

${ }^{31}$ E. Anderson, M. J. Almond, W. Matthews, Spectrochim. Acta A, 133, (2014), 326-334

32 J. Madejova, FTIR techniques in clay mineral studies, Vib, Spectrosc., 31(1), (2003), 1-10, DOI: [https://doi.org/10.1016/S0924-2031(02)00065-6] 